\title{
An evaluation of the Lancer Coagulyzer in the measurement of the one-stage prothrombin time
}

\author{
LINDA M. ROWLANDS AND A. C. K. LAWRENCE \\ From the Haematology Department, Northern General Hospital, Sheffield
}

SYNOPSIS An evaluation of a photoelectric clot timer, the Lancer Coagulyzer, in measuring the onestage prothrombin time has been carried out. The machine is considered to provide reliable results on correctly taken samples without interference by plasma bilirubin, only rarely failing to detect clotting in turbid plasma using a wide range of thromboplastins. The apparatus is useful where there is a sufficient number of samples to be tested.

This report is concerned with the performance of an automatic photoelectric clot timer (Lancer Coagulyzer) in the measurement of the one-stage prothrombin time. The machine is capable of detecting clots in other coagulation tests but this report is confined to the one-stage prothrombin test. The form of the report is based on a proposed testing schedule for evaluation of equipment in haematology laboratories (Sharp, 1970).

\section{Basic Information}

The cost in 1974 was $£ 3400$ from Wright Scientific Limited, Kenley, Surrey, agents for Sherwood Received for publication 1 September 1975
Medical Industries Incorporated, Missouri, USA. The cost in June 1975 was $£ 3990$ exclusive of value added tax.

\section{Description of Apparatus}

The apparatus consists of a 'manual plasma pipettor' for loading the cuvettes with $0 \cdot 1 \mathrm{ml}$ of sample and a machine (figure) which consists of a turntable holding a maximum of 60 clear polystyrene, round in section, reaction cuvettes, reagent delivery pipettes, a photoelectric detector of optical density change, and a printout device; $0.1 \mathrm{ml}$ or $0.2 \mathrm{ml}$ of the reagent can be added in turn from both, or the second of two, magnetically-stirred reservoirs. The reservoirs

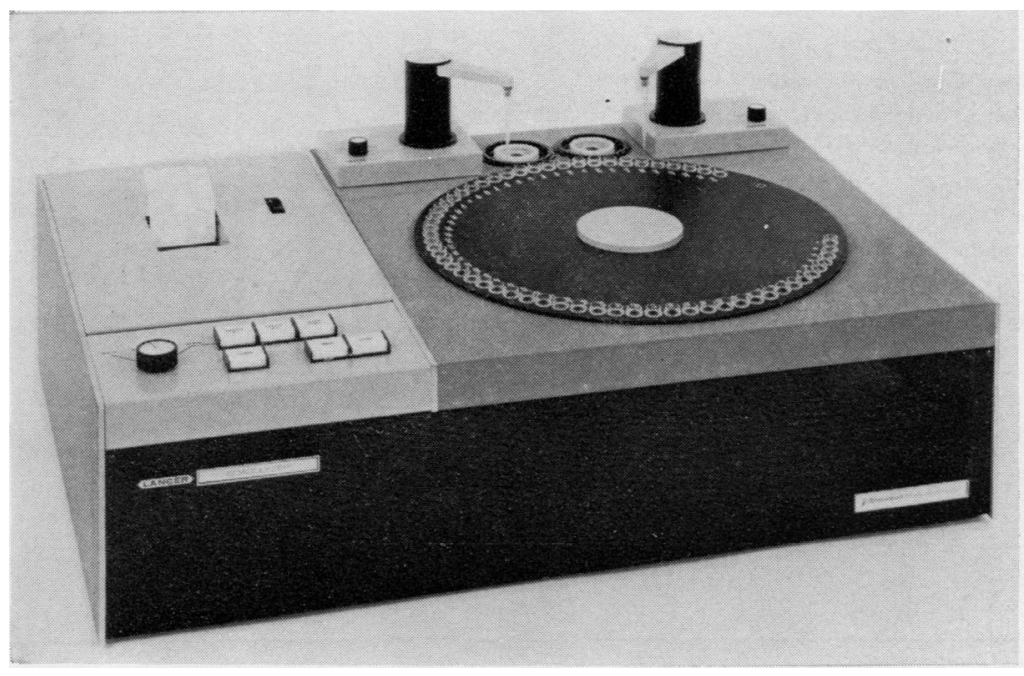

Figure The Lancer Coagulyzer. 
are conical in shape to ensure minimum wastage of reagent but truncated to form a small $(1.3 \mathrm{~cm}$ diameter) flat bottom. Each reservoir holds up to $20 \mathrm{ml}$ of reagent. Lids with a central hold are provided to minimize evaporation, and remain in position while the machine is in use. There are separate disposable tips for the reagent delivery pipettes and the 'plasma pipettor' which are not interchangeable. The second reservoir is warmed to $37.5^{\circ} \mathrm{C}$ by a heater block. The reaction cuvettes remain at the ambient temperature before the start of the test cycle. A modification allowing refrigeration of the samples before passage under the first reagent delivery pipette has been introduced on subsequent machines. The cuvette enters a separate heated aluminium block, maintained at $37^{\circ} \mathrm{C}$, for a minimum of 3 , and a maximum of 9 , minutes before the final reagent addition, which starts the clot timer. The reaction cuvette is then maintained in the heated block while the reaction takes place, in a light path containing a diffuser and a filter passing visible light at a wavelength above $600 \mathrm{~nm}$. After a delay of 9 seconds optical density changes activate the clot-sensing circuit.

The minimum and maximum incubation times and the maximum reaction time are controlled with four switch positions labelled PT-1, PT-2, APTT, and MAN. PT-1 is for single reagent additions. PT- 2 and APTT are for double reagent additions, with varying incubation times before the addition of a second reagent. MAN is for manual control of the turntable position, reagent additions, and commencement of timing.

The maximum allowable reaction time is given in column 7 of table $I$, and the minimum time the cuvette remains in the reaction position is given in column 6 . If the result is less than this minimum time, it is printed at once but the turntable does not move until the minimum time has elapsed. When the reaction time is in excess of this minimum time, the turntable moves as the result is being printed. Columns 4 and 5 give the incubation times before the test, depending on the delays due to the individual reaction times of the preceding samples. Columns 2 and 3 indicate which reagent reservoirs are used in each switch position. The machine has two turbidity settings to allow for variation in turbidity of the reagents.

\section{Rate of Analysis}

The machine is ready for use within 5 minutes of switching on. The cuvette heater block and reagent reservoir are rapidly warmed and so the machine is readily available for use even out of laboratory hours.

The turntable holds 60 samples. The maximum rate of performance of the one-stage prothrombin time on samples with coagulation times less than 30 seconds is 120 per hour, with another $4 \frac{1}{2}$ minutes before the first sample is tested.

\section{Standards}

No standards are provided by the manufacturer.

\section{Samples and Capillary Blood}

The machine is unsuitable for timing clots in capillary samples taken directly from the patient. There are no automatic facilities for rejection of clotted, turbid or haemolysed samples.

\section{Printout}

The results are printed on a continuous paper roll as a vertical list in seconds to the first decimal place alongside the number of the position on the turntable which the cuvette occupies. It is not possible to adjust the space between results, making it more difficult to arrange for the results to be printed on to prepared adhesive labels. The manufacturers state that the machine can be interfaced with a computer.

\section{Space and Services}

The machine measures $74 \mathrm{~cm}$ long $\times 50.5 \mathrm{~cm}$ wide with an overall height of $30 \mathrm{~cm}$ and so requires 90 $\mathrm{cm}$ of $75 \mathrm{~cm}$ width bench to allow for necessary air circulation at the rear. Electricity 240 volts AC with a 5 amp circuit is all that is required.

\begin{tabular}{|c|c|c|c|c|c|c|}
\hline \multirow{2}{*}{$\begin{array}{l}\text { Switch Position } \\
1\end{array}$} & \multicolumn{2}{|c|}{ Reagent Reservoirs } & \multicolumn{2}{|c|}{$\begin{array}{l}\text { Incubation Time prior to Test } \\
\text { (seconds) }\end{array}$} & \multicolumn{2}{|c|}{$\begin{array}{l}\text { Time Cuvette remains at Reaction } \\
\text { Position (seconds) }\end{array}$} \\
\hline & $\begin{array}{l}\text { First Addition } \\
\text { (Labelled 2) } \\
2\end{array}$ & $\begin{array}{l}\text { Second Addition } \\
\text { (Labelled 1) } \\
3\end{array}$ & $\begin{array}{l}\text { Maximum } \\
4\end{array}$ & $\begin{array}{l}\text { Minimum } \\
5\end{array}$ & $\begin{array}{l}\text { Minimum } \\
6\end{array}$ & $\begin{array}{l}\text { Maximum } \\
7\end{array}$ \\
\hline $\begin{array}{l}\text { PT-1 } \\
\text { PT-2 } \\
\text { APTT }\end{array}$ & $\begin{array}{l}- \\
+ \\
+\end{array}$ & $\begin{array}{l}+ \\
+ \\
+\end{array}$ & $\begin{array}{l}540 \\
540 \\
540\end{array}$ & $\begin{array}{l}180 \\
180 \\
360\end{array}$ & $\begin{array}{l}30 \\
30 \\
60\end{array}$ & $\begin{array}{l}90 \\
90 \\
90\end{array}$ \\
\hline
\end{tabular}

Table I Timing of Coagulyzer turntable movement 


\section{Staff Training and Instruction Book}

The machine is easy to use and no special training course is required. The instruction book has 96 pages. The method of operation of the machine is described in three pages, maintenance on one page, and the machine specifications and descriptions occupy 15 pages. Eight pages contain a description of the preliminary setting up of the instrument on delivery, which are not clearly separated in the index from the method of operation. The specifications are incomplete.

\section{Maintenance and Service}

No maintenance is required apart from confirmation of the incubator block and second reagent reservoir temperature and replacement of printer paper and fuse as needed. Other service is available through the agents.

\section{Reagents}

The machine is designed to be used with any thromboplastin reagent using one or other of the two turbidity settings.

\section{Evaluation of Instrumentation}

\section{SENSITIVITY}

On three separate occasions dilutions of pooled normal plasma, ranging from 10 to $100 \%$, were made in physiological saline. Plasma pools 1 and 2 were of average turbidity. The optical density at $600 \mathrm{~nm}$ was 0.354. Plasma pool 3 was of greater than average turbidity. One-stage prothrombin times were measured on each dilution by visual inspection, and by using the Coagulyzer in both of the turbidity settings. The tests were done in duplicate, and the mean values are presented in table II.
Using the setting for less turbid reagents, the Coagulyzer was satisfactory for all dilutions above $15 \%$, and none of the $10 \%$ dilutions was measured. Using the setting for more turbid reagents, the Coagulyzer was less sensitive to clot formation, and only dilutions over $25 \%$ were always satisfactory and no clot formation was detected on any dilution below $25 \%$.

Measurements were made of the one-stage prothrombin time using 10 different jaundiced plasmas, serum bilirubins ranging from $2 \cdot 0-21 \cdot 0 \mathrm{mg} / \mathrm{dl}$. The results in table III show that the bilirubin present did not interfere with the detection of clotting using the Coagulyzer.

\section{LIMITATION OF VOLUME OF REAGENT}

The manufacturers recommend $0.5 \mathrm{ml}$ of reagent in the reservoir in excess of the volume to be removed by the pipette.

\section{Evaluation of Performance of the One-stage Pro- thrombin Time}

\section{METHODS}

The one-stage prothrombin time was carried out using a locally prepared acetone-dried extract of

\begin{tabular}{lll}
\hline $\begin{array}{l}\text { Serum Bilirubin } \\
(\mathrm{mg} / \mathrm{dl})\end{array}$ & $\begin{array}{l}\text { Mean One-stage Prothrombin Times } \\
\text { (seconds) }\end{array}$ \\
\cline { 2 - 3 } & Coagulyzer & Visual Methods \\
\hline 2.0 & 11.3 & 13.0 \\
2.3 & 9.9 & 12.0 \\
5.0 & 10.0 & 11.5 \\
7.0 & 9.7 & 11.0 \\
8.0 & 20.8 & 22.5 \\
8.0 & 16.5 & 18.5 \\
10.0 & 12.9 & 13.0 \\
12.0 & 14.6 & 13.0 \\
16.0 & 17.1 & 18.5 \\
21.0 & 10.2 & 11.0 \\
\hline
\end{tabular}

Table III Effect of bilirubin on clot detection using the Coagulyzer

\begin{tabular}{|c|c|c|c|c|c|c|c|c|c|}
\hline \multirow{2}{*}{$\begin{array}{l}\text { Dilutions } \\
\%\end{array}$} & \multicolumn{3}{|l|}{ Pool 1} & \multicolumn{3}{|l|}{ Pool 2} & \multicolumn{3}{|l|}{ Pool 3} \\
\hline & Visual & $\begin{array}{l}\text { Coagulyzer } \\
1\end{array}$ & 2 & Visual & $\begin{array}{l}\text { Coagulyzer } \\
1\end{array}$ & 2 & Visual & $\begin{array}{l}\text { Coagulyzer } \\
1\end{array}$ & 2 \\
\hline $\begin{array}{r}100 \\
80 \\
60 \\
50 \\
40 \\
30 \\
25 \\
20 \\
15 \\
10\end{array}$ & $\begin{array}{l}12 \cdot 0 \\
13 \cdot 5 \\
14 \cdot 5 \\
16 \cdot 5 \\
20 \cdot 0 \\
25 \cdot 5 \\
29 \cdot 0 \\
35 \cdot 0 \\
51 \cdot 0 \\
87 \cdot 0\end{array}$ & $\begin{array}{l}10 \cdot 7 \\
11 \cdot 5 \\
13 \cdot 3 \\
15 \cdot 0 \\
17 \cdot 7 \\
21 \cdot 9 \\
26 \cdot 5 \\
31 \cdot 6 \\
52 \cdot 3 \\
90 \cdot 0^{1}\end{array}$ & $\begin{array}{l}11 \cdot 2 \\
12 \cdot 1 \\
14 \cdot 0 \\
15 \cdot 7 \\
18 \cdot 6 \\
23 \cdot 8 \\
28 \cdot 2 \\
90 \cdot 0^{1} \\
90 \cdot 0^{1} \\
90 \cdot 0^{1}\end{array}$ & $\begin{array}{l}12.0 \\
13.0 \\
15.0 \\
16.0 \\
18.5 \\
25.5 \\
30.5 \\
34.0 \\
50.5 \\
86.0\end{array}$ & $\begin{array}{l}10 \cdot 5 \\
11 \cdot 6 \\
13 \cdot 4 \\
15 \cdot 2 \\
17 \cdot 2 \\
22 \cdot 6 \\
26 \cdot 4 \\
31 \cdot 7 \\
51 \cdot 3 \\
90 \cdot 0^{1}\end{array}$ & $\begin{array}{l}10 \cdot 8 \\
11 \cdot 9 \\
13 \cdot 7 \\
15 \cdot 8 \\
18 \cdot 1 \\
23 \cdot 0 \\
26 \cdot 7 \\
90 \cdot 0^{1} \\
90 \cdot 0^{1} \\
90 \cdot 0^{1}\end{array}$ & $\begin{array}{l}12 \cdot 0 \\
13 \cdot 0 \\
15 \cdot 0 \\
17 \cdot 0 \\
20 \cdot 0 \\
26 \cdot 0 \\
32 \cdot 0 \\
38 \cdot 5 \\
55 \cdot 0 \\
85 \cdot 0\end{array}$ & $\begin{array}{l}10 \cdot 9 \\
11 \cdot 7 \\
13.6 \\
15.6 \\
18 \cdot 2 \\
23.5 \\
28 \cdot 8 \\
34.9 \\
90 \cdot 0^{1} \\
90 \cdot 0^{1}\end{array}$ & $\begin{array}{l}10 \cdot 8 \\
12 \cdot 0 \\
13 \cdot 9 \\
15 \cdot 7 \\
18 \cdot 1 \\
24 \cdot 7 \\
90 \cdot 0^{1} \\
90 \cdot 0^{1} \\
90 \cdot 0^{1} \\
90 \cdot 0^{1}\end{array}$ \\
\hline
\end{tabular}

Table II One-stage prothrombin times in seconds on dilutions of pooled plasma measured visually and with the Coagulyzer using both turbidity settings

Clot not detected. Turbidity setting 1 for less turbid reagents. Turbidity setting 2 for more turbid reagents. 
human brain, with a calcium concentration and test $\mathrm{pH}$ known to give optimum results using a visual method, and with the British Comparative Thromboplastin (BCT) supplied by courtesy of Dr Leon Poller, using the PT-2 position. Five commercially prepared calcium thromboplastins-Dade thromboplastin C, Dade activated thromboplastin, Ortho brain thromboplastin, Hemodiagnostica Stago calcium thromboplastin, and Hyland thromboplastin -were used with the PT-1 operating sequence.

The EEL prothrombin meter was used as described by the manufacturers. Visual one-stage prothrombin times were carried out using a standard method (Biggs, 1972). The results of the duplicate times of the test plasmas were compared with the times of a normal plasma and are expressed as a ratio.

\section{PRECISION}

Replicate successive tests of normal plasma and plasma from patients on oral anticoagulants were carried out using the locally prepared reagent. The mean test time and the coefficient of variation are shown in table IV.

\section{CORRELATION WITH OTHER METHODS}

Two hundred and seventy-four plasmas from individual patients on oral anticoagulants were compared using the Coagulyzer, and EEL prothrombin meter, and the visual method. Table $V$ shows a close

\begin{tabular}{llll}
\hline Source of Plasma & $\begin{array}{l}\text { Number of } \\
\text { Tests }\end{array}$ & $\begin{array}{l}\text { Mean } \\
\text { (seconds) }\end{array}$ & $\begin{array}{l}\text { Coefficient } \\
\text { of Variation } \\
\%\end{array}$ \\
\hline $\begin{array}{l}\text { A pool of normal subjects } \\
\text { A pool of patients on oral }\end{array}$ & 50 & 13.09 & 0.261 \\
$\begin{array}{l}\text { anticoagulant therapy } \\
\text { A second pool of patients } \\
\text { on oral anticoagulant } \\
\text { therapy }\end{array}$ & 40 & 19.28 & 1.01 \\
\hline
\end{tabular}

Table IV Reproducibility of the one-stage prothrombin time using the Coagulyzer

\begin{tabular}{|c|c|c|c|c|}
\hline \multirow[t]{2}{*}{ Methods } & \multirow{2}{*}{$\begin{array}{l}\text { Number of } \\
\text { Comparisons }\end{array}$} & \multirow{2}{*}{$\begin{array}{l}\text { Correlation } \\
\text { Coefficient }\end{array}$} & \multicolumn{2}{|c|}{ Regression Line } \\
\hline & & & Slope & Intercept \\
\hline $\begin{array}{l}\text { Visual and } \\
\text { Coagulyzer }\end{array}$ & 274 & 0.988 & 1.04 & -0.10 \\
\hline $\begin{array}{l}\text { Coagulyzer and } \\
\text { EEL coagulation } \\
\text { meter }\end{array}$ & 274 & 0.963 & 0.79 & 0.31 \\
\hline $\begin{array}{l}\text { Visual and EEL } \\
\text { coagulation } \\
\text { meter }\end{array}$ & 100 & 0.929 & 0.76 & 0.35 \\
\hline
\end{tabular}

Table V Comparison of one-stage prothrombin time ratios on a series of plasmas using three methods on each correlation between ratios of one-stage prothrombin times produced using the Coagulyzer and a visual method. The slope of the linear regression line is very close to $1 \cdot 0$. The comparisons involving the 0 EEL meter and the visual method and the EEL meter 흠 and the Coagulyzer show a smaller correlation co- $\bar{\omega}$ efficient and a slope of the linear regression line less $\overparen{\nabla}$ close to $1 \cdot 0$.

Results of clotting times of one-stage prothrombin tests using this machine may differ from those $\vec{\circ}$ obtained by other methods. In comparison with $\overrightarrow{\vec{\omega}}$ other methods used in this investigation the $\mathrm{Co}-\mathrm{O}$ agulyzer results were consistently shorter.

During the course of measuring 20000 prothrombin times since the machine has been in routine 0 use, all prothrombin time results in excess of $50 \omega$ seconds have been repeated by a visual method. ${ }_{-}^{\omega}$ When the time recorded was between 50.0 and 89.9 을 seconds, the comparison with the visual method was on every occasion satisfactory.

When the maximum time of 90 seconds is recorded, this is usually due to an excessively long co- $\frac{\rho}{J}$ agulation time. On a few occasions the Coagulyzer $\overrightarrow{0}$ had failed to detect the slight change in optical $/$ density which had occurred as the sample clotted. This resulted in a markedly shorter time using the visual method. This situation occurred with some extremely turbid plasmas but sometimes this appeared to be due to a less opaque clot. When there is $\frac{0}{\varnothing}$ spontaneous coagulation in the cuvette before the $\varrho$ addition of calcium the result is usually printed as $\overrightarrow{\vec{O}}$ 90 seconds but occasionally as 9 seconds when co- 3 agulation is beginning before recalcification. The machine can theoretically produce a false result of 90 . seconds due to failure to add reagents to the cuvette.

It would appear to be essential that all results $:$ which record the maximum or minimum time should 3 be repeated by another method.

\section{SUITABILITY FOR USE WITH VARIOUS}

THROMBOPLASTINS

Five commercially available thromboplastins, de- $\frac{D}{0}$ tailed in the methods section, and the BCT were tested in the Coagulyzer. One-stage prothrombin o times were measured on five plasmas from normal $N$ subjects and on 30 plasmas from patients receiving N oral anticoagulant therapy using the Coagulyzer $\omega$ and a visual method. This sequence was repeated for each thromboplastin using the same series of samples $\stackrel{\circ}{\simeq}$ of normal and patient plasmas. Each oral anti- $\cong$ coagulant plasma result was expressed as a ratio compared with the mean normal result using that thromboplastin. The results are shown in table VI. $\vec{\Phi}$ The optical densities of the reagents were measured $\frac{?}{\mathbb{Q}}$ with the reagent ready for use as a recalcified reagent $\stackrel{\varrho}{\varrho}$ with the commercial preparations and as a reagent 2 


\begin{tabular}{|c|c|c|c|c|c|}
\hline \multirow[t]{2}{*}{ Thromboplastin } & \multirow{2}{*}{$\begin{array}{l}\text { Optical Density at } 600 \mathrm{~nm} \\
\text { of Suspension for Use }\end{array}$} & \multirow[t]{2}{*}{ Number of Comparisons } & \multirow[t]{2}{*}{ Correlation Coefficient } & \multicolumn{2}{|c|}{ Regression Line } \\
\hline & & & & Slope & Intercept \\
\hline $\begin{array}{l}\text { British Comparative } \\
\text { Dade } \\
\text { Hemodiagnostica Stago } \\
\text { Dade C } \\
\text { Ortho } \\
\text { Hyland }\end{array}$ & $\begin{array}{l}4 \cdot 800 \\
1 \cdot 475 \\
0 \cdot 500 \\
0 \cdot 343 \\
0 \cdot 251 \\
\text { Not measured }\end{array}$ & $\begin{array}{l}\mathbf{3 0} \\
\mathbf{3 0} \\
\mathbf{3 0} \\
\mathbf{3 0} \\
\mathbf{3 0} \\
\mathbf{3 0}\end{array}$ & $\begin{array}{l}0.992 \\
0.930 \\
0.983 \\
0.962 \\
0.960 \\
0.959\end{array}$ & $\begin{array}{l}1 \cdot 17 \\
0.83 \\
0.92 \\
0.96 \\
0.84 \\
0.88\end{array}$ & $\begin{array}{r}0.28 \\
0.31 \\
0 \cdot 14 \\
0 \cdot 10 \\
0.23 \\
0 \cdot 15\end{array}$ \\
\hline
\end{tabular}

Table VI Comparison of one-stage prothrombin time ratios using the Coagulyzer and a visual method and various thromboplastins

without calcification with the BCT. The correlation coefficient derived from this comparison of the Coagulyzer and a visual method was independent of the turbidity of the reagent.

If thromboplastins are used which produce very short coagulation times with normal plasmas by the visual method, the coagulation time recorded by the Coagulyzer may be very close to the minimum recordable time of 9 seconds.

\section{RELIABILITY}

During the trial period of the first 14 months of use the machine has been repaired twice. On the first occasion it was necessary to revert to another method, and on the second occasion a replacement machine was provided while the repair was being carried out. There was a total of $3 \frac{1}{2}$ working days during which no machine was available. Both faults were failure of the turntable to move; this was due to the operation of a fail-safe temperature switch attached to the turntable motor. Apart from this the machine has functioned well with no minor problems.

\section{RUNNING COSTS}

Present running costs are estimated for 1000 tests for a laboratory doing 500 prothrombin tests per week, each test being performed in duplicate. The disposable items used are as follows. Reagent reservoirs cost $9.35 \mathrm{p}$ each, approximately $50 \mathrm{p}$ per 1000 tests. Pipette tips for the manual plasma pipettor are approximately $1.0 \mathrm{p}$ each, depending on the quantity ordered, approximately $£ 10$ per 1000 tests. Two pipette tips are required each day for the reagent delivery by the Coagulyzer. These cost $2.5 \mathrm{p}$ each, approximately $50 \mathrm{p}$ per 1000 tests. Reaction cuvettes cost $0.945 \mathrm{p}$ each, $£ 18.90$ per 1000 tests. The reagents used cannot be assessed as the price depends on the thromboplastin used, but reagent costs should be identical with most currently used visual methods as there is very little wastage in reagent reservoirs. One technician is required to operate the machine but extra technician time is available during the analysis.

After the first year of guarantee a comprehensive maintenance contract including parts, travelling, and labour is available. In June 1975 this costs $£ 240$ per annum.

\section{ANXIETY FACTORS}

The mechanical performance of the machine and the degree of skill and application required to operate it give rise to no difficulty for any haematology technician of experience.

The printing of the maximum possible time is a source of anxiety. While the maximum time may be due to an excessively long coagulation time, the possibility of failure of reagent supply is always present. There is no indication system to show that the reagent reservoirs are empty or that the reagent is not delivered.

Recording of the shortest coagulation time of 9 seconds is usually due to an unsatisfactory sample which is partially clotted. Difficulties can occur in adding extra cuvettes to the turntable once the sequence, using the PT-2 switch position, has begun. Using the PT-2 and APTT positions, the sensing device for the second addition pipette position acts on that of the first addition pipette position. In these circumstances, during a test sequence, should an attempt be made to add samples in such a way that a blank space passes under the second addition pipette while a cuvette is under the first addition pipette, the turntable will continue to rotate, even though the first addition pipette is delivering reagent. This results in the reagent either being delivered from the first addition pipette into an inappropriate cuvette further on in the sequence, or into an inaccessible part of the machine. This can be prevented by filling any intermediate spaces with empty cuvettes which have clotting times recorded as 90 seconds. Otherwise once the test cuvettes have ceased to pass under the first addition pipette the batch of tests must be completed separately, and the turntable allowed to return to the starting position, with a consequent waiting time between small batches of tests which is often between 5 and 10 minutes.

If the above circumstances seem likely to occur in routine use, the first batch may be held before empty cuvette spaces have reached the first addition pipette 
position, using the HOLD switch.

\section{General Conclusion of Usefulness}

The machine is quickly available for use out of hours, providing a standard method of clot detection regardless of the time of day. It seems to us economically justified for measuring the one-stage prothrombin time alone where samples are received and separated at the rate of two or more per minute. The machine will then be in constant use.

Davey et al (1972) compared the Lancer Coagulyzer with a fibrin switch instrument, using one thromboplastin in the measurement of the one-stage prothrombin time, and showed a similar precision with both instruments and good correlation between the two methods of clot detection with samples with prothrombin ratios up to $2 \cdot 7$. Our results were similar to those of Davey et al when comparing the Coagulyzer with the EEL prothrombin meter and a visual method.

No comments were made by Davey and colleagues regarding difficulties. We found that while jaundiced plasma samples were measured satisfactorily, clots were occasionally not detected in turbid plasmas and diluted plasma samples. Alteration of the turbidity setting may overcome the difficulties arising from a more turbid reaction mixture, but this also reduces the capacity of the machine to detect small changes in optical density.

Incorrectly taken, partially clotted samples occasionally gave minimum clotting times, while the remainder were detected before the machine was loaded. We consider that repeat tests with a visual method should be carried out on samples giving maximum or minimum times. Any remaining doubts after this are resolved in the usual way, with fresh samples.

The results with each thromboplastin tested in the machine correlated well with clotting times assessed visually. There appears to be no reason why clot detection in other clotting tests should not be satisfactorily carried out, but this was not assessed.

The apparatus has proved acceptable to all laboratory workers who have used it.

The instruction manual could be improved from the point of view of an experienced laboratory worker by clearly separating the method of operation from the rest of the large book, by giving a more complete specification and omitting or supplying separately the long section on the coagulation mech- $\mathrm{S}$ anism and the general principles of coagulation tets.

We consider that where there is a sufficient workload of one-stage prothrombin times the machine is a useful asset.

\section{References}

Biggs, R. (1972). Human Blood Coagulation, Haemostasis and Thrombosis, p. 609. Blackwell, Oxford.

Davey, F. R., Fiske, M. L., and Maltby, A. (1972). Evaluation of a photoelectric automatic prothrombin analyzer. Amer. J. clin. Path., 58, 687-692.

Sharp, A. A. (1970). Proposed testing schedule for evaluation of equipment in haematology laboratories. J. clin. Path., 23, 333-335. 